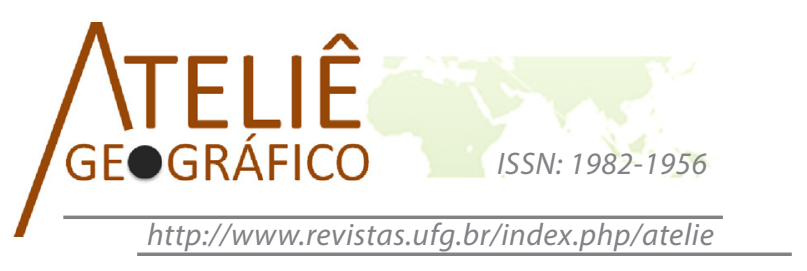

\title{
Dinâmica do uso e cobertura das terras nos municípios de Castelo do Piaui e Juazeiro do Piauí, Nordeste, Brasil
}

\author{
Dynamics of the use and coverage of land in municipalities \\ of Castelo do Piaui and Juazeiro do Piauí, Northeastern \\ Brazil
}

\section{Dinámica de uso y cobertura del suelo en los municipios de Castelo de Piauí y Juazeiro do Piauí, Noreste de Brasil}

\author{
Francílio de Amorim dos Santos \\ Instituto Federal do Piauí / Campus Piripiri \\ francilio.amorim@ifpi.edu.br \\ Cláudia Maria Sabóia de Aquino \\ Universidade Federal do Piauí / \\ Campus Universitário Ministro Petrônio Portela. \\ cmsaboia@gmail.com
}

\section{Resumo}

O estudo teve como objetivo analisar a dinâmica do uso e cobertura das terras relacionando-a as variações econômicas nos municípios de Castelo do Piauí e Juazeiro do Piauí. A análise da dinâmica do uso e cobertura das terras baseou-se na análise de imagens do satélite Landsat $5 \mathrm{TM}$ possibilitaram constatar que houve redução das classes de cobertura vegetal do tipo Caatinga Arbórea e agropecuária (lavouras, pecuária e extração vegetal) e aumento da classe Caatinga Arbustiva. A redução da caatinga arbórea é resultado do i) aumento dos cultivos temporários em 50\%, de 1997 para 2009 e ii) aumento da extração de madeira para a produção de carvão e lenha, respectivamente, em 18,2 \% e 4,4\%, de 2004 para 2009. Os possíveis estágios de sucessão ecológica e aumento da caatinga arbustiva devemse ao i) aumento das áreas destinadas aos cultivos permanentes na proporção de 18,5\%; ii) redução dos rebanhos bovino, ovino e caprino em 2,4\%, de 1997 e 2009, e iii) a diminuição da produção mineral. Os dados sociais revelam necessidade de investimentos em saúde, geração de empregos e, principalmente, em educação, devido o baixo nível de instrução.

Palavras-chave: Área Suscetível à Desertificação, Dados Econômicos, Cobertura Vegetal. 


\begin{abstract}
The objective of this study was to analyze the dynamics of land use and land cover by linking it to economic variations in the municipalities of Castelo do Piauí and Juazeiro do Piauí. The analysis of the land use and land cover dynamics was based on the Landsat 5 TM satellite imagery analysis, which showed that there was a reduction of the Arborea Caatinga and agricultural ranching (crop, livestock and vegetal extraction) and class increase classes Shrub Caatinga. The reduction in tree savanna is the result of i) an increase of temporary crops by $50 \%$ from 1997 to 2009 and ii) increase in coal extraction and burning, respectively, $18.2 \%$ and $4.4 \%$, from 2004 to 2009 . Possible stages of ecological succession and increased shrub savanna are due to i) increase in the areas intended for permanent crops at the rate of $18.5 \%$; ii) reduction of beef cattle, sheep and goats by $2.4 \%$ in 1997 and 2009, and iii) the decrease in mineral production. Social data reveals need for investments in health, job creation, and especially in education due to their low level of education.
\end{abstract}

Keywords: Susceptible Area Desertification, Economics, Coverage of Lands.

\begin{abstract}
Resumen
El objetivo del estudio fue analizar la dinámica de uso y cobertura del suelo en relación con los cambios económicos en los municipios de Castelo do Piauí y Juazeiro do Piauí. El uso de análisis dinámico y cobertura de la tierra se basa en la imagen de satélite Landsat 5 TM análisis permitió ver que había una reducción del tipo de vegetación arbórea clases de cobertura de Caatinga Arbórea y la agricultura (cultivos, ganadería y extracción de la planta) y el aumento de la clase Caatinga Arbustiva. La reducción en la sabana de árboles es el resultado de i) un aumento de los cultivos temporales en un 50\% de 1997 a 2009 y ii) aumento de la extracción de carbón y la quema, respectivamente, 18,2\% y 4,4\%, 2004 a 2009. Posibles etapas de sucesión ecológica y el aumento de la sabana de arbustos se deben a i) el aumento de las superficies destinadas a cultivos permanentes a la tasa del 18,5\%; ii) la reducción de ganado vacuno, ovejas y cabras en un 2,4\% en 1997 y 2009, y iii) la disminución de la producción de minerales. Datos sociales revela necesidad de invertir en la salud, la creación de empleo, y especialmente en la educación debido a su bajo nivel de educación.
\end{abstract}

Palabras clave: Área Susceptible de Desertificación, Economia, cobertura de Tierras.

\title{
Introdução
}

O marco histórico das discussões mundiais acerca do fenômeno da desertificação data da Conferência Internacional das Nações Unidas para o Combate à Desertificação (UNCOD), em Nairóbi, no Quênia, em 1977. No Rio de Janeiro, em 1992, durante a Conferência Internacional das Nações Unidas sobre o Meio Ambiente e Desenvolvimento (CNUMAD), foi elaborado documento denominado Agenda 21, cujo Capítulo 12 foi dedicado a tratar da temática da desertificação. O referido documento define desertificação como "[...] a degradação do solo em áreas áridas, semi-áridas e subúmidas secas, resultante de diversos fatores, inclusive de variações climáticas e de atividades humanas" (BRASIL, 1995, p.149).

A degradação dessas terras é produto de variações climáticas associadas ao uso inadequado dos solos devido prática das atividades humanas, conforme aponta o 
Programa de Ação Nacional de Combate à Desertificação e Mitigação dos Efeitos da Seca - PAN-Brasil (BRASIL, 2004). As consequências da desertificação são múltiplas e comprometem os recursos hídricos, o solo, a cobertura vegetal e a qualidade de vida da população das áreas afetadas.

O conhecimento das causas que levam ao desencadeamento do processo de desertificação expressa fundamental necessidade de estudos, que primem por articular vários parâmetros ou indicadores, que servirão como forma de conhecer o real dimensionamento das áreas suscetíveis ou já em processo de degradação/desertificação. Isso revela a necessidade do desenvolvimento de estudos nos municípios de Castelo do Piauí e Juazeiro do Piauí, que foram apontados em estudo de Aquino e Oliveira (2012), como áreas suscetíveis à desertificação.

As regiões áridas e semiáridas estendem-se por todo o planeta e ocupam 1/3 de toda a superfície da Terra, onde vive cerca de $1 / 6$ da população mundial (MATALLO JÚNIOR, 2001). De acordo com Nimer (1988), a citada do planeta é diretamente afetada pelo fenômeno da desertificação, devido degradação dos ecossistemas, ressecamento ambiental que, por sua vez, origina-se de mudanças climáticas locais e do uso inadequado dos solos mediante as ações antrópicas.

Mediante as ações antrópicas, o processo de degradação e desencadeamento da desertificação assola quase metade da superfície do globo, pois todos os continentes encontram-se ameaçados. Desse modo 37\% das zonas áridas estão na África, 33\% na Ásia e 14\% na Austrália, alguns também são encontrados na América e no Sul da Europa. As áreas áridas cobrem $40 \%$ das terras, $66 \%$ já são afetados pela desertificação, porém $10 \%$ a $20 \%$ estão seriamente degradadas. Das terras áridas atingidas pela desertificação, $93 \%$ são pastagens, $6 \%$ são culturas de sequeiro e $1 \%$ são culturas irrigadas. Nesse contexto, $1 / 3$ da humanidade já está sendo afetada pelo processo de desertificação (FRANCE, 2011).

Nos últimos anos o processo de desertificação tem sido acelerado pela expansão demográfica, que gera problemas socioeconômicos e acentua a fragilidade natural e intensfica o uso das terras (EMEKA, 2013). Na busca por compreender as causas da degradação ambiental que resultam da expansão das atividades humanas, atualmente, vários pesquisadores em todo o mundo têm desenvolvido pesquisas utilizando-se da aplicação de sensores de alta resolução espectral, almejando contribuir para o monitoramento e gerenciamento ambiental, de acordo com Aquino et al. (2014).

Diante da complexidade do fenômeno da desertificação, o presente estudo buscou analisar a dinâmica do uso e cobertura das terras relacionando-a as variações econômicas, nos municípios de Castelo do Piauí e Juazeiro do Piauí, apontadas por estudo de Aquino e Oliveira (2012) como Áreas Suscetíveis à desertificação (ASD). Os referidos municípios estão localizados na região Nordeste do Brasil (NEB) e apresentam variações econômicas que podem ser decorrentes do uso inadequado das terras e resultar no desencadeamento do processo de degradação/desertificação. Nessa ótica, o conhecimento da dinâmica do uso e cobertura das terras e das variações socioeconômicas possibilitará o desenvolvimento de politicas públicas na área em estudo, que apresenta fragilidade climática natural à desertificação. 


\section{Metodologia}

Para o estudo empregou-se metodologia com abordagem qualitativa e quantitativa. A primeira está relacionada ao uso, análise e interpretação da variação dos dados econômicos, enquanto a segunda, diz respeito à quantificação desses dados e das classes de cobertura das terras. Por sua vez, a pesquisa possui natureza explicativa, pois busca identificar os fatores que influenciam a dinâmica do uso e cobertura das terras e as variações econômicas nos municípios de Castelo do Piauí e Juazeiro do Piauí.

\section{Caracterização geográfica da área em estudo}

O presente estudo foi desenvolvido nos municípios de Castelo do Piauí e Juazeiro do Piauí (Figura 1), localizados na Macrorregião do Meio-Norte, Território de Desenvolvimento dos Carnaubais e $6^{\circ}$ Aglomerado de Municípios (AGM) (PIAUÍ, 2006). Suas sedes municipais localizam-se, respectivamente, a $158 \mathrm{~km}$ e $184 \mathrm{~km}$ de Teresina, capital do estado do Piauí. Os referidos municípios possuem importantes fontes historiográficas, registros fósseis, vegetação de transição Caatinga, Cerrado e Carnaubal, além de formações rochosas areníticas.

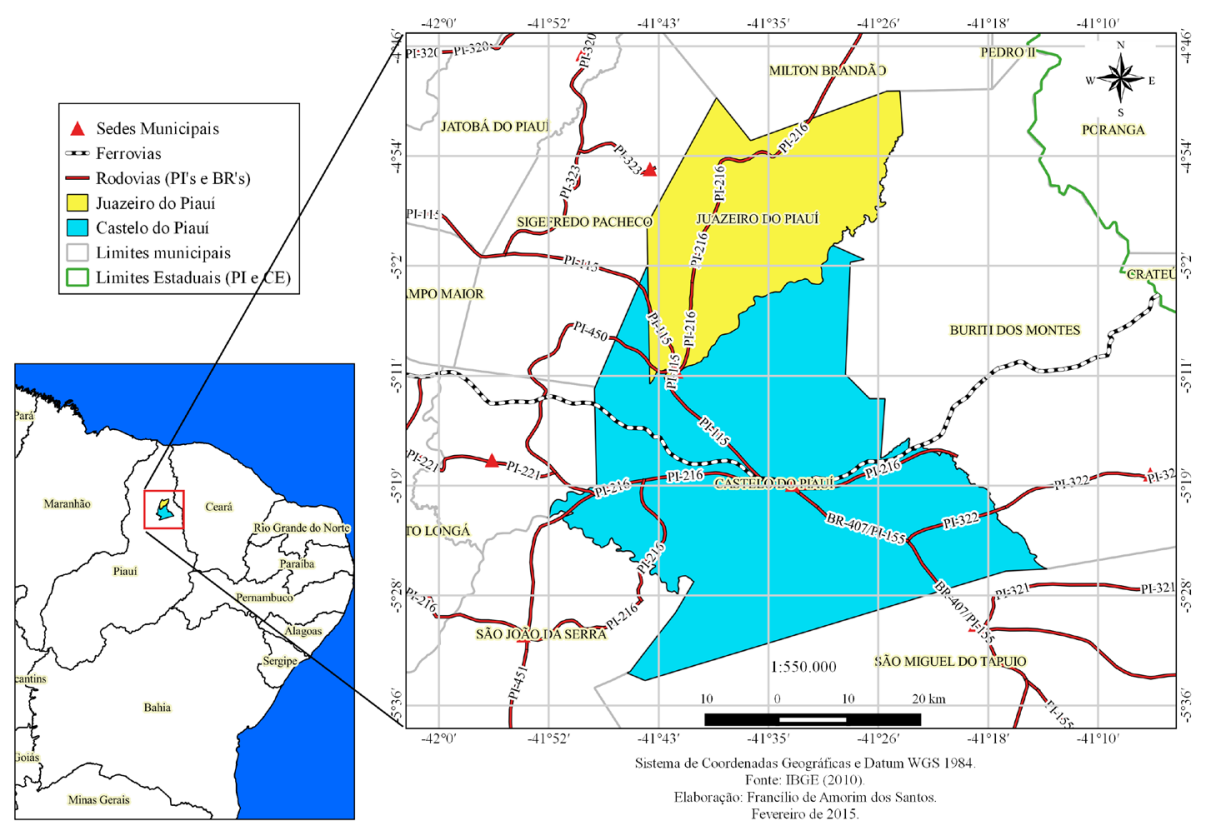

Figura 1. Localização dos municípios de Castelo do Piauí e Juazeiro do Piauí. Fonte: IBGE (2010). 
Castelo do Piauí possui área com 2.035,2 km², limitando-se ao norte com Pedro II, ao sul com São Miguel do Tapuio, a leste Área de Litígio entre Piauí e Ceará, a oeste com Campo Maior, Alto Longá e São João da Serra. Sua sede municipal localiza-se às Coordenadas Geográficas 05¹9 '19 'S e 41³3 '10 ”O (AGUIAR e GOMES, 2004a). Juazeiro do Piauí possui área de $827,2 \mathrm{~km}^{2}$, limitando-se ao norte com Sigefredo Pacheco e Milton Brandão, ao sul com Castelo do Piauí e Buriti dos Montes, a leste com Buriti dos Montes, a oeste Castelo do Piauí e Sigefredo Pacheco. Sua sede situa-se às Coordenadas

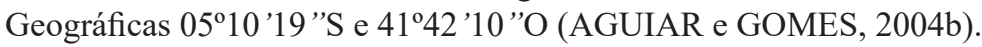

O relevo dos referidos municípios é constituído por determinadas formações geológicas, que possibilitam a exploração de rochas ornamentais, arenitos e siltitos, com reservas superiores a $18.000 .000 \mathrm{~m}^{3}$. Este AGM exerce liderança que responde por quase $100 \%$ das exportações piauienses de produtos de base mineral, conferindo-lhes a denominação de Polo de Mineração e Garimpo de Rochas Ornamentais (CEPRO, 2008). Logo, há grande relevância na composição do valor total dos produtos gerados em 2007, pois cerca de $97 \%$ da produção resultou na comercialização e transferência de rochas ornamentais e calcário (BRASIL, 2009).

De acordo com dados do Censo de 2010, realizado pelo Instituto Brasileiro de Geografia e Estatística (IBGE, 2012), o município de Castelo do Piauí possui uma população de 18.336 habitantes, sendo que 11.479 habitantes moram na zona urbana, $62,60 \%$ do total da população, e 6.857 na zona rural, correspondendo a $37,40 \%$ da população. Desse modo, consta-se que o município apresenta uma densidade demográfica de $9,1 \mathrm{hab} . / \mathrm{km}^{2}$.

Por sua vez, o Censo do IBGE (2010) aponta que a população de Juazeiro do Piauí é constituída por de 4.757 habitantes, dos quais 1.479 residem na zona urbana (31,1\% do total) e 3.278 na zona rural (68,9\% da população), resultando em uma densidade demográfica de $5,8 \mathrm{hab} . / \mathrm{km}^{2}$.

\section{Procedimento metodológico para análise do uso e cobertura das terras}

Os sistemas de processamento e análise de imagens através de programas computacionais possibilitam aplicar técnicas de processamento de imagens, por meio de operações numéricas que são aplicadas às mesmas (FLORENZANO, 2008). Tais procedimentos são essenciais para o monitoramento da degradação/desertificação em Áreas Suscetíveis à Desertificação (ASD).

Desse modo, foram adquiridas imagens do satélite Landsat 5 TM referentes aos anos de 1985 e 2009, com resolução espacial de 30 metros, considerando a menor presença de nuvens, conforme Quadro 1. As imagens são distribuídas gratuitamente através do site <http://earthexplorer.usgs.gov/> do United States Geological Service (Serviço Geológico dos Estados Unidos - USGS). O sistema Landsat foi desenvolvido pela NASA (National Aeronautics and Space Administration) e possibilita a aquisição de dados espaciais, espectrais e temporais da superfície terrestre, de forma global, sinóptica e repetitiva (AQUINO e VALLADARES, 2013). 
Quadro 1. Características das imagens do satélite Landsat 5 TM, imageadas dos municípios de Castelo do Piauí e Juazeiro do Piauí.

\begin{tabular}{|c|c|c|c|c|c|}
\hline \multicolumn{3}{|c|}{1985} & \multicolumn{3}{c|}{2009} \\
\hline Órbita/Ponto & Datas & Resolução Espacial & Órbita/Ponto & Datas & Resolução Espacial \\
\hline $218 / 63$ & 29 de set. & 30 metros & $218 / 63$ & 01 de out. & 30 metros \\
\hline $218 / 64$ & 29 de set. & 30 metros & $218 / 64$ & 01 de out. & 30 metros \\
\hline
\end{tabular}

Fonte: Pesquisa direta. Santos (Org.), 2015.

Após a aquisição das imagens junto ao USGS, procedeu-se à elaboração do mapa dos tipos de uso e cobertura das terras através de classificação supervisionada e, posteriormente, conferida em campo. Nesse sentido, o procedimento inicial foi realizar a composição falsa cor das Bandas 5, 4 e 3 (RGB) por meio da ferramenta data management tools opção composite bands, no ArcGIS 10. Para realizar a classificação supervisionada das imagens Landsat 5, para os anos de 1985 e 2009, foi criado um arquivo do tipo shapefile (vetor), formato polígono, no ArcCatalog. A nova shapefile foi utilizada como base para vetorização das seguintes classes: caatinga arbórea, caatinga arbustiva, agropecuária + solo exposto.

Os dados obtidos no IBGE referentes às culturas temporárias e permanentes obtidos foram: as áreas plantadas e colhidas, em hectares, e produção, em toneladas; os dados dos efetivos dos rebanhos bovino, ovino e caprino foi o número de cabeças de cada rebanho. Os referidos dados foram analisados de forma comparativa com os dados de uso e cobertura das terras para os anos de 1985 e 2009, cujo objetivo foi compreender a relação existente entre a degradação/desertificação e a dinâmica socioeconômica da área em estudo. Nesse sentido, o Quadro 2 apresenta as características dos dados utilizados para o presente estudo, desde os dados das imagens do satélite Landsat 5 TM aos dados obtidos no IBGE.

Quadro 2. Características dos dados utilizados para o estudo da dinâmica do uso e cobertura das terras nos municípios de Castelo do Piauí e Juazeiro do Piaú́.

\begin{tabular}{|l|l|l|l|}
\hline Tipos de dado & Fonte & Link para acesso & Objetivo \\
\hline Carvão vegetal e lenha & IBGE & www.cidades.ibge.gov.br & $\begin{array}{l}\text { Identificação do nível de } \\
\text { desmatamento }\end{array}$ \\
\hline $\begin{array}{l}\text { Culturas temporárias } \\
\text { e permanentes (áreas } \\
\text { plantadas e colhidas, e } \\
\text { produção) }\end{array}$ & IBGE & www.cidades.ibge.gov.br & $\begin{array}{l}\text { Identificação da dinâmica } \\
\text { do aumento/redução da } \\
\text { degradação da cobertura } \\
\text { vegetal }\end{array}$ \\
\hline $\begin{array}{l}\text { Efetivos dos rebanhos } \\
\text { bovino, ovino e caprino }\end{array}$ & IBGE & www.cidades.ibge.gov.br & $\begin{array}{l}\text { Identificação da dinâmica } \\
\text { do aumento/redução da } \\
\text { degradação da cobertura } \\
\text { vegetal }\end{array}$ \\
\hline $\begin{array}{l}\text { Imagens do satélite } \\
\text { Landsat 5 TM }\end{array}$ & USGS & www.ibge.gov.br & $\begin{array}{l}\text { Análise da dinâmica da } \\
\text { degradação da cobertura } \\
\text { vegetal }\end{array}$ \\
\hline
\end{tabular}

Fonte: Pesquisa direta. Santos (Org.), 2015. 


\section{Resultados e discussão}

Os municípios de Castelo do Piauí e Juazeiro do Piauí tem sua economia baseada nas práticas agropecuárias e de extração vegetal e mineral, cuja dinâmica será exposta a seguir. Entretanto, de modo geral, após a análise dos dados e imagens pode-se inferir que houve expansão das áreas destinadas aos cultivos agrícolas dos tipos permanentes e temporários, e extração vegetal, por outro lado, houve redução dos efetivos dos rebanhos e da extração mineral.

\section{Dinâmica do uso e cobertura das terras nos anos de 1985 e 2009}

A cobertura vegetal influencia diretamente na diminuição da erosão ao interceptar as precipitações, favorecendo o surgimento de detritos vegetais na superfície do solo, ambos desempenhando papel amortecedor ou absorvedor de energia, fazendo diminuir a velocidade do vento e aumentando a turbulência da passagem do ar, como propõe Tricart (1977).

A vegetação presente nos municípios de Castelo do Piauí e Juazeiro do Piauí é constituída por variadas fisionomias em diversos estágios de conservação e de regeneração, sendo encontradas algumas áreas ainda bastante conservadas. Desse modo, a estrutura vegetacional da área em estudo apresenta formações baixas e abertas, destacando-se o estrato herbáceo, as arbóreas mais encorpadas e o cerrado rupestre. Este último encontra-se disposto sobre os afloramentos rochosos e entre as linhas de drenagem temporárias, caracterizando-se por possuir plantas de pequeno porte e bastante espaçadas (ALBINO, 2005).

As imagens do satélite Landsat 5 TM, permitiram identificar três classes de uso e cobertura das terras em Castelo do Piauí e Juazeiro do Piauí. Desse modo. Logo, pode-se afirmar que de 1985 para 2009 ocorreram pequenas modificações no padrão de uso e cobertura das terras nos referidos municípios (Figura 2), possivelmente devido à dinâmica pluviométrica, com escassez de chuvas.

Por meio da Tabela 1 foi possível afirmar que houve redução das atividades agropecuárias em $0,3 \%$, de 1985 para 2009. Entretanto, a vegetação do tipo caatinga arbórea teve redução de 1,6\%, enquanto constatou-se aumento de $1,9 \%$ na classe caatinga arbustiva. A redução da caatinga arbórea e aumento da caatinga arbustiva podem ser explicados pela dinâmica das atividades agropecuárias e das atividades relacionadas à extração vegetal e mineral, como será exposto a seguir.

Tabela 1. Distribuição das áreas e porcentagens das classes de uso e cobertura das terras, nos municipios de Castelo do Piauí e Juazeiro do Piauí, comparação entre os anos de 1985 e 2009.

\begin{tabular}{l|c|c|c|c}
\hline \multirow{2}{*}{ Tipo de vegetação/uso das terras } & \multicolumn{2}{|c|}{$\mathbf{1 9 8 5}$} & \multicolumn{2}{c}{$\mathbf{2 0 0 9}$} \\
\cline { 2 - 5 } & Área $\left.\mathbf{( k m}^{\mathbf{2}}\right)$ & $\mathbf{\%}$ & Área $\left(\mathbf{k m}^{\mathbf{2}}\right)$ & $\mathbf{\%}$ \\
\hline Agropecuária + Solo exposto & $1.285,2$ & 44,9 & $1.276,6$ & 44,6 \\
\hline Caatinga Arbórea & 363,8 & 12,7 & 317,7 & 11,1 \\
\hline Caatinga Arbustiva & $1.213,4$ & 42,4 & $1.268,1$ & 44,3 \\
\hline Total & $\mathbf{2 . 8 6 2 , 4}$ & $\mathbf{1 0 0}$ & $\mathbf{2 . 8 6 2 , 4}$ & $\mathbf{1 0 0}$ \\
\hline
\end{tabular}

Fonte: Imagens do satélite Landsat 5 TM, considerando os anos de 1985 a 2009. 

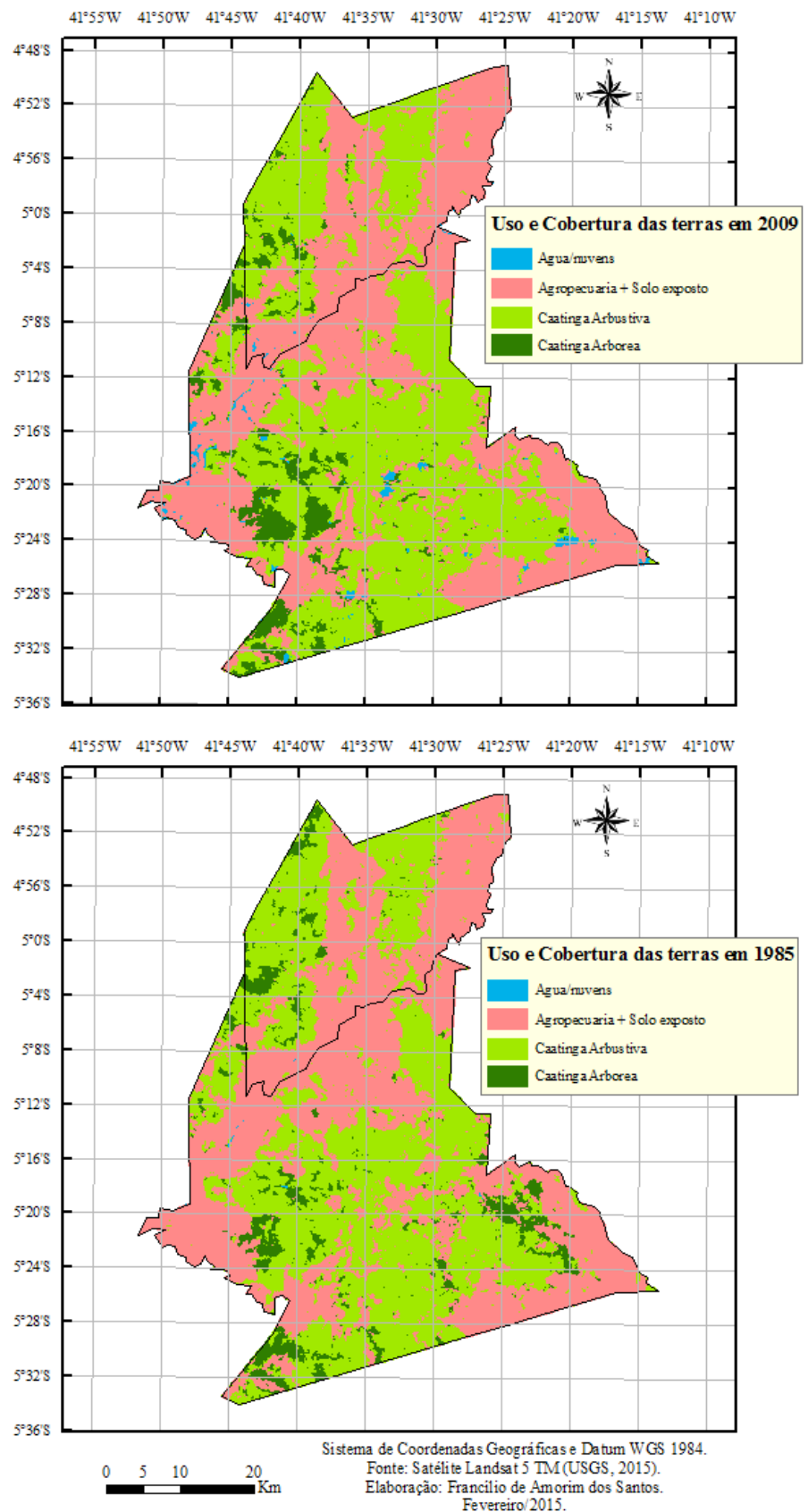

Figura 2. Uso e ocupação das terras nos municípios de Castelo do Piauí e Juazeiro do Piauí, comparação entre os anos de 1985 e 2009. Fonte: Pesquisa direta. Santos (Org.), 2015. 


\section{Variação dos aspectos econômicos em Castelo do Piauí e Juazeiro do Piauí}

Para discutir as variações no padrão de proteção oferecida pela cobertura vegetal da área estudada, particularmente os tipos de cultivo em caráter temporário ou permanente, foram considerados para análise apenas os dados dos anos de 1997 e 2009. Pois os dados anteriores ao primeiro ano não corresponderiam a realidade atual, devido processo emancipatório dos municípios de Buriti dos Montes, em 1993, e Juazeiro do Piauí, em 1997.

Cabe, incialmente, destacar que a economia piauiense apresentou grande dinamismo a partir da década de 1990, devido principalmente ao aumento da produção de soja, castanha de caju e cana-de-açúcar e ainda de hortifrutigranjeiros como a banana, manga, laranja e alho (MACAMBIRA, 2000).

Por meio da Tabela 2 pode-se inferir que houve aumento de $50 \%$ da área destinada ao plantio de culturas temporárias, de 1997 a 2009, resultando em aumento da degradação e redução da proteção oferecida pela cobertura vegetal. Por outro lado, houve aumento da área plantada destinada às culturas permanentes, na proporção de $18,5 \%$, resultando em aumento da proteção e redução da degradação.

O aumento das culturas temporárias da ordem de 50\% entre os anos analisados permite inferir uma tendência de aumento da área degradada, constatação essa corroborada com os dados da Tabela 2 que indicam redução da classe caatinga arbórea e aumento da classe Caatinga Arbustiva. Ressalta-se, ainda, que essa pequena variação pode ser justificada mediante realização de estudos posteriores para análise de dados climáticos na área em questão.

Tabela 2. Síntese da variação entre os anos de 1997 e 2009 das áreas plantadas (culturas temporárias e permanentes) em Castelo do Piauí e Juazeiro do Piauí.

\begin{tabular}{l|c|c|cl}
\hline \multirow{2}{*}{ Culturas } & \multicolumn{2}{|c|}{ Área plantada (ha) } & \multicolumn{2}{c}{ Variação entre 1989 e 2009 } \\
\cline { 2 - 5 } & $\mathbf{1 9 9 7}$ & $\mathbf{2 0 0 9}$ & Percentagem & Consequência \\
\hline Temporárias & 3.633 & 5.265 & Aumento de 50\% & $\begin{array}{l}\text { Aumento da degradação/ Redução } \\
\text { da proteção }\end{array}$ \\
\hline Permanentes & 389 & 461 & Aumento de $18,5 \%$ & $\begin{array}{l}\text { Aumento da proteção/ Redução da } \\
\text { degradação }\end{array}$ \\
\hline
\end{tabular}

Fonte: Dados adaptados da Pesquisa Agropecuária Municipal Piauí do IBGE, considerando os anos de 1997 e 2009.

Os dados dispostos na Tabela 3 apresentam a variação da produtividade na área em estudo, considerando os anos de 1989 e 2009. Em observação à Tabela 4, pode-se afirmar que houve aumento na produtividade de todas as culturas, exceto o cultivo de mandioca. Destaca-se que o aumento da produtividade deveu-se de forma diretamente proporcional ao tamanho da área destinada ao plantio, logo, aumento o tamanho da área desmatada e, consequente, redução da proteção e aumento da degradação ambiental. 
Tabela 3. Área plantada, produção bruta, produtividade e sua variação entre os anos de 1989 e 2009, nos municípios de Castelo do Piauí e Juazeiro do Piauí.

\begin{tabular}{|c|c|c|c|c|c|c|c|}
\hline \multirow{2}{*}{ Anos } & \multicolumn{2}{|c|}{$\begin{array}{l}\text { Área plantada } \\
\text { (ha) }\end{array}$} & \multicolumn{2}{|c|}{$\begin{array}{c}\text { Produção bruta } \\
\text { (ton.) }\end{array}$} & \multicolumn{2}{|c|}{$\begin{array}{l}\text { Produtividade } \\
\text { (ton./ha) }\end{array}$} & \multirow{2}{*}{$\begin{array}{c}\text { Variação da } \\
\text { produtividade } \\
\text { entre } 1989 \text { e } \\
2009(\%)\end{array}$} \\
\hline & 1989 & 2009 & 1989 & 2009 & 1989 & 2009 & \\
\hline Arroz & 850 & 365 & 1.300 & 235 & 1,529 & 1,559 & $+2,0$ \\
\hline Cana-de-açúcar & 1.000 & 250 & 45.000 & 15.000 & 45 & 60 & +33 \\
\hline Feijão & 3.500 & 2.160 & 1.050 & 420 & 0,3 & 0,564 & +88 \\
\hline Mandioca & 3.000 & 175 & 36.000 & 853 & 12 & 8,533 & $-28,9$ \\
\hline Melancia & 300 & 5 & 120 & 125 & 0,4 & 25 & +6.150 \\
\hline Milho & 4.300 & 2.310 & 2.580 & 493 & 0,6 & 0,359 & $+40,2$ \\
\hline Banana & 50 & $2 *$ & 83 & $24 *$ & 1,66 & $12 *$ & $+622,9^{*}$ \\
\hline Castanha de caju & 7.000 & 461 & 1.449 & 142 & 0,207 & 0,661 & $+219,3$ \\
\hline
\end{tabular}

*Foi considerado para análise o último ano de área plantada e produção registrada, ou seja, 2002. Fonte: Dados adaptados da Pesquisa Agropecuária Municipal Piauí do IBGE, considerando os anos de 1989 e 2009.

Os dados dispostos na Tabela 4 correlacionam-se aos tipos de uso e cobertura das terras nos anos considerados (1985 e 2009), que aponta redução da caatinga arbórea (classe de maior proteção) e aumento da caatinga arbustiva.

Consideraram-se os anos de 1997 e 2009 para análise dos rebanhos bovino, ovino e caprino, posto que tenham ocorrido emancipações municipais, como expostos anteriormente. Os dados dos efetivos dos três rebanhos, também, sofreram interferência no número de cabeças, estes apresentaram redução. Os dados dispostos na Tabela 4 apontam redução de 2,4\% em relação ao total dos efetivos dos três rebanhos, de 1997 para 2009, o que proporcionou um pequeno aumento na proteção da cobertura vegetal.

Tabela 4. Síntese da variação dos rebanhos (bovino, ovino e caprino) entre os anos de 1997 e 2009 nos municípios de Castelo do Piauí e Juazeiro do Piauí.

\begin{tabular}{|c|c|c|c|c|c|c|c|c|}
\hline \multirow{4}{*}{ Variáveis } & \multicolumn{8}{|c|}{ Rebanho } \\
\hline & \multicolumn{2}{|c|}{ Bovino (B) } & \multicolumn{2}{|c|}{ Ovino (O) } & \multicolumn{2}{|c|}{ Caprino (C) } & \multicolumn{2}{|c|}{ Totais $(\mathrm{B}+\mathrm{O}+\mathrm{C})$} \\
\hline & \multicolumn{8}{|c|}{ Anos } \\
\hline & 1997 & 2009 & 1997 & 2009 & 1997 & 2009 & 1997 & 2009 \\
\hline Cabeças & 20.347 & 21.751 & 19.862 & 20.314 & 44.709 & 40.793 & 84.918 & 82.858 \\
\hline
\end{tabular}

\begin{tabular}{|l|c|c|}
\hline Variação entre 1997 e 2009 & $\begin{array}{c}\text { Porcentagem/ } \\
\text { Cabeças }\end{array}$ & Diminuição de 2,4\% \\
\cline { 2 - 3 } & Consequência & $\begin{array}{c}\text { Redução da degradação/ } \\
\text { Aumento da proteção }\end{array}$ \\
\hline
\end{tabular}

Fonte: Dados adaptados da Pesquisa Pecuária Municipal Piauí do IBGE, considerando os anos de 1997 e 2009. 
A caprinocultura foi o único dentre os três rebanhos que apresentou redução. O número de cabeças diminuiu em $8,7 \%$. Tal redução possivelmente tenha permitido pequena regeneração da cobertura vegetal, através de sucessão ecológica. Pois a prática da caprinocultura foi observada, principalmente, em áreas de caatinga arbustiva.

Por meio da Tabela 5, pode-se afirmar que houve significativo aumento na produção de carvão vegetal e lenha de 2004 a 2009, respectivamente, de 18,2 \% e 4,4\%. Tal fato resulta em significa redução da proteção da cobertura vegetal e aumento da degradação. Os resultados merecem atenção, pois os números retratam o aumento da retirada da cobertura vegetal e diminuição da proteção dada pela cobertura vegetal ao solo. O aumento da extração vegetal pode ser relacionado aos dados de cobertura vegetal e uso da terra dispostos na Figura 1, pois essa apresentou redução da caatinga arbórea da ordem de $1,6 \%$, enquanto a caatinga arbustiva teve aumento de $1,9 \%$.

Destaca-se que o MMA em parceria com o Programa das Nações Unidas para o Desenvolvimento - PNUD e o Global Environment Facility - GEF tem desenvolvido no bioma Caatinga o Projeto de Demonstrações de Manejo Integrado de Ecossistemas e de Bacias Hidrográficas na Caatinga - GEF Caatinga, que visa o manejo integrado de ecossistemas com conservação e uso sustentável dos recursos naturais, como exemplo cite-se a difusão do fogão ecológico, que é 50\% mais eficiente na conversão energética se relacionado ao fogão à lenha convencional (BRASIL, 2007).

Tabela 5. Síntese da variação da produção de cera de carnaúba (pó), carvão vegetal e lenha, nos municípios de Castelo do Piauí e Juazeiro do Piauí, período de 2004 a 2009.

\begin{tabular}{c|c|c|cc}
\hline $\begin{array}{c}\text { Extração } \\
\text { vegetal }\end{array}$ & \multicolumn{2}{|c|}{ Quantidade produzida (ton.) } & \multicolumn{2}{c}{ Variação entre 2004 e 2009 } \\
\cline { 2 - 5 } & $\mathbf{2 0 0 4}$ & $\mathbf{2 0 0 9}$ & Percentagem & Consequência \\
\hline $\begin{array}{c}\text { Carvão } \\
\text { vegetal }\end{array}$ & 712 & 842 & $\begin{array}{c}\text { Aumento de } \\
18,2 \%\end{array}$ & $\begin{array}{c}\text { Aumento da degradação/ } \\
\text { Redução da proteção }\end{array}$ \\
\hline Lenha & 13.640 & 14.236 & $\begin{array}{c}\text { Aumento de } \\
4,4 \%\end{array}$ & $\begin{array}{c}\text { Aumento da degradação/ } \\
\text { Redução da proteção }\end{array}$ \\
\hline
\end{tabular}

Fonte: Adaptados do banco de dados do IBGE, considerando os anos de 2004 e 2009.

Os municípios de Castelo do Piauí e Juazeiro do Piauí possuem jazidas de siltito e folhelhos, conhecidos, respectivamente, como quartzito e ardósia já em exploração, cujas rochas são conhecidas desde 1950. A ECB rochas Ornamentais do Brasil LTDA, mineradora de capital multinacional, desde 1998 explora ardósia e quartzito ornamental, em Castelo do Piauí e Juazeiro do Piauí.

A referida empresa possui reconhecimento internacional no setor de extração de rochas ornamentais, beneficiando e exportando ardósias e quartzitos. Por concentrar quase $100 \%$ das exportações piauienses de produtos de base mineral, os municípios receberam o título de Pólo de Mineração e Garimpo de Rochas Ornamentais (BRASIL, 2008). Os anos de maior participação da ECB no comércio piauiense deram-se em 2003, 2004 e 2005, respectivamente com 19,09\%, 19,47\%, 19,27\% (Figura 3), mantendo uma porcentagem média de $14,08 \%$ de participação no valor da produção comercializada entre as 20 principais empresas do setor, no Estado. 
Silva (2007) em seu estudo ressalta que a mineração gera dano ambiental devido os depósitos estéreis e de rejeitos, bem como degradação visual da paisagem, fato constatado na área de estudo, conforme mostra a Figura 4.

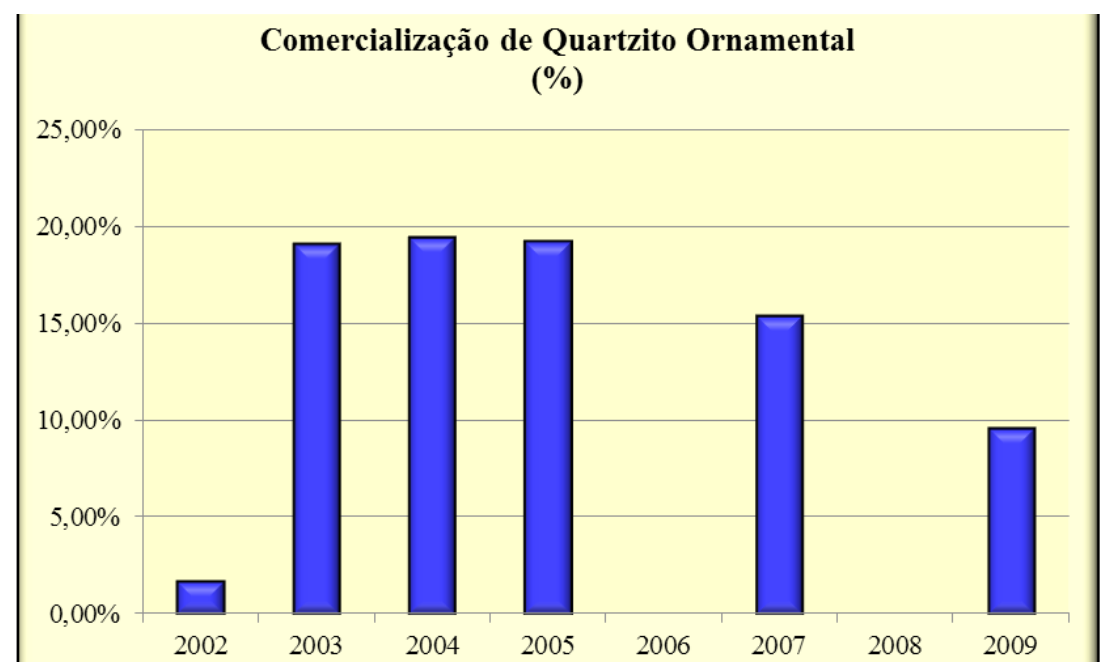

Figura 3. Participação da ECB Rochas Ornamentais na comercialização de Quartzito

Ornamental do Piauí, no período de 2002 a 2009.

Fonte: Anuário Mineral Brasileiro (BRASIL, 2003 a 2010)ํ.

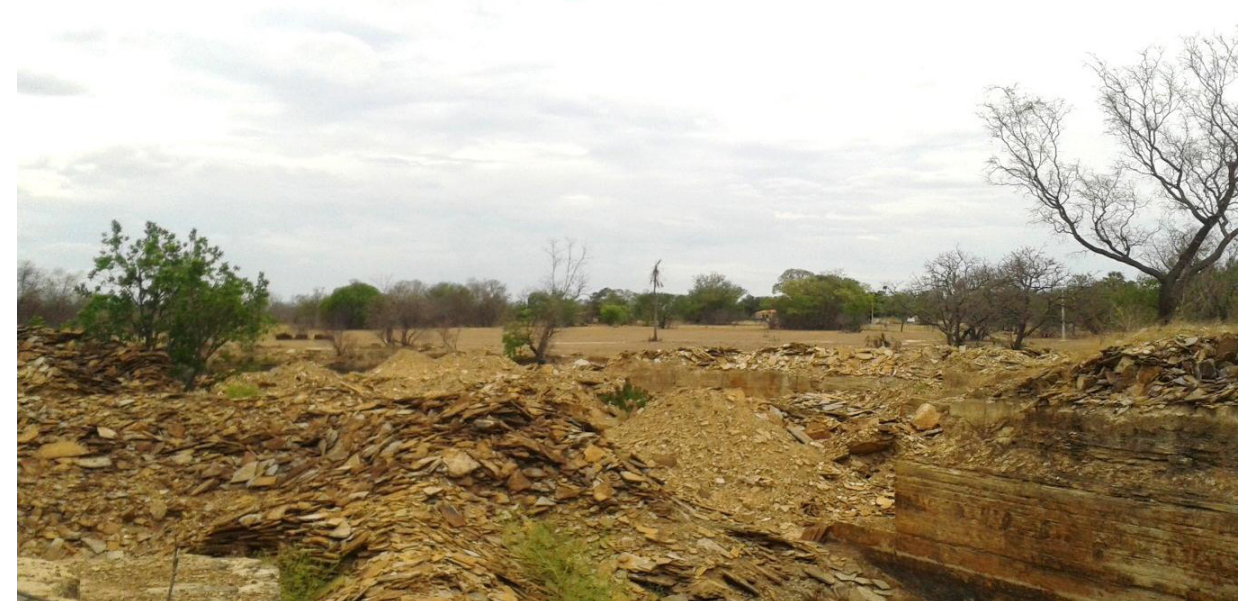

Figura 4. Rejeitos estéreis acumulados em área de extração mineral, no Vale da Bacia do rio Poti, com degradação visual da paisagem devido desmatamento. Fonte: Pesquisa direta. Santos (Org.), 2015.

1. Não foram encontrados dados da comercialização de quartzito para os anos de 2006 e 2008. 
Embora a primeira atividade demandada pela extração mineral seja a retirada da vegetação, a redução da extração mineral posterior ao ano de 2005 na área em estudo, seja pela ECB ou pelos trabalhadores autônomos, permitiu uma pequena regeneração da cobertura vegetal, o que pode ser relacionado aos dados do uso e cobertura das terras (1985 e 2009). Entretanto, deve-se atentar para os resíduos produzidos pela citada atividade e degradação visual da paisagem.

\section{Conclusões}

A análise da dinâmica do uso e cobertura das terras permitiu inferir que as modificações ocorridas de 1985 para 2009 resultaram na perda de caatinga arbórea, classe de cobertura vegetal de maior proteção, e aumento da caatinga arbustiva. A redução da caatinga arbórea deve-se, principalmente, ao aumento da extração vegetal para a produção de carvão e lenha, bem como da expansão dos cultivos temporários. Por outro lado, o aumento das áreas destinadas aos cultivos permanentes, à redução do rebanho caprino e da extração mineral permitiram estágios de sucessão ecológica e regeneração da caatinga arbustiva, em Castelo do Piauí e Juazeiro do Piauí.

$\mathrm{O}$ aumento das áreas destinadas ao plantio de culturas permanentes e temporárias aponta, respectivamente, aumento da proteção e redução da proteção da cobertura vegetal oferecida aos solos. Aliado ao aumento dos cultivos temporários, o aumento dos efetivos bovino e ovino, aumento da extração vegetal para a produção de carvão e lenha associado aos $46,2 \%$ dos solos que apresentam alta erodibilidade, pode levar à área em estudo ao desencadeamento do processo de desertificação.

O estudo foi de suma importância ao fornecer dados de uso e ocupação das terras castelense e juazeirense. Porém, faz-se necessário que os dados acima expostos sejam integrados ao conhecimento da dinâmica geoambiental, o que possibilitará uma visão macro e, consequentemente, facilitará o desenvolvimento de diagnósticos e elaboração de um planejamento territorial adequado, principalmente, nos referidos municípios que apresentam fragilidade natural e risco de desertificação.

\section{Referências}

AGUIAR, R. B.; GOMES, J. R. C. (Org.). Projeto cadastro de fontes de abastecimento por água subterrânea, estado do Piauí: diagnóstico do município de Castelo do Piauí. Fortaleza: CPRM - Serviço Geológico do Brasil, 2004a.

. Projeto cadastro de fontes de abastecimento por água subterrânea, estado do Piauí diagnóstico do município de Juazeiro do Piauí. - Fortaleza: CPRM - Serviço Geológico do Brasil, 2004b.

ALBINO, R. S. Florística e fitossociologia da vegetação de cerrado rupestre de baixa altitude e perfil socioeconômico da atividade mineradora em Castelo do Piaui e Juazeiro do Piauí, Brasil. Dissertação (Mestrado em Desenvolvimento e Meio Ambiente). Universidade Federal do Piauí - UFPI. Teresina, 2005. 
ALENCAR, M. T. Considerações sobre a formação, organização do território e da sociedade piauiense. In: Semiárido Piauiense: Educação e Contexto. SILVA, C.M.S.; LIMA, E.S.; CANTALICE, M.L.; ALENCAR, M.T.; SILVA, W.A.L. (Orgs.). Campina Grande: INSA. 2010b. p.35-62.

AQUINO, C. M. S.; OLIVEIRA, J. G. B. Estudos sobre desertificação no Piauí. Sapiência. Teresina-PI, jan/fev/mar, nº 30, ano VIII, 2012.

AQUINO, C. M. S.; OLIVEIRA, J. G. B.; ALMEIDA, J. A. P. Variações ambientais, econômicas e sociais em áreas com risco de desertificação no núcleo de São Raimundo Nonato - Piauí. Revista de Geografia (UFPE), V. 31, No. 2, 2014.

BAPTISTA, J. G. Geografia Física do Piauí. 2a edição. Teresina: COMEPI, 1981.

BRASIL. Conferência das Nações Unidas sobre o Meio Ambiente e Desenvolvimento: de acordo com a Resolução n $n^{\circ}$ 44/228 da Assembléia Geral da ONU, de 22-12-89, estabelece uma abordagem equilibrada e integrada das questões relativas a meio ambiente e desenvolvimento: Agenda 21. - Brasília: Câmara dos Deputados, Coordenação de Publicações, 1995.

BRASIL. Ministério de Minas e Energias. Departamento Nacional de Produção Mineral. Anuário Mineral Brasileiro. Brasília, DF: DNPM, 2009.

BRASIL. Ministério do Meio Ambiente. Atlas das áreas susceptíveis à desertificação do Brasil. Secretaria de Recursos Hídricos. Universidade Federal da Paraíba; Marcos Oliveira Santana (Org.). Brasília: 2007.

BRASIL. Ministério do Meio Ambiente. Secretaria de Recursos Hídricos. Programa de Ação Nacional de Combate à Desertificação e Mitigação dos Efeitos da Seca PANBrasil. Brasília: MMA. 2004.

CEPRO - Fundação Centro de Pesquisas Econômicas e Sociais do Piauí. Diagnostico e Diretrizes para o Setor Mineral do Estado do Piauí. DNPM, 2008.

COSTA, J. M. Estudo fitossociológico e sócio-ambiental de uma área de cerrado com potencial melitófilo no município de Castelo do Piauí, Piauí, Brasil. Dissertação (Mestrado em Desenvolvimento e Meio Ambiente). Universidade Federal do Piauí UFPI. Teresina, 2005.

CPRM - Companhia de Pesquisa de Recursos Minerais. Ministério de Minas e Energia. Mapas estaduais de geodiversidade: Piauí. Rio de Janeiro: CPRM. 2006. Documento cartográfico em arquivo vetorial. Disponível em http://geobank.sa.cprm.gov.br. Acesso em janeiro de 2014.

EMEKA, E. E. Drought and Desertification as they affect Nigerian Environment. Journal of Environmental Management and Safety, vol. 4, n 1, p.45-54. Nsukka - Nigéria. 2013.

FLORENZANO, T. G. Sensoriamento Remoto para Geomorfologia. In: FLORENZANO, T. G. (Org.). Geomorfologia: conceitos e tecnologias atuais. São Paulo: Oficina de Textos. 2008, p.36-71. 
FRANCE. Ministère des Affaires Étrangères et Européennes. France's external action against land degradation and desertification. Desertification and land degradation, a challenge for usall. 2011.

IBGE - Instituto Brasileiro de Geografia e Estatística. Banco de dados. Censo 2010. 2012. Disponível em: www.ibge.gov.br. Acesso em dezembro de 2013. de 2013.

. Cidades. 2013. Disponível em: www.cidades.ibge.gov.br. Acesso em dezembro

. Malha municipal digital do Brasil: situação em 2010. Rio de Janeiro: IBGE, 2012. Disponível em: <ftp://geoftp.ibge.gov.br/malhas_digitais/>. Acesso em 27 de agosto de 2015. de Janeiro.

. Pesquisa Agropecuária Municipal Piauí - anos de 1989, 1997, 2003 e 2009. Rio Janeiro.

Pesquisa Pecuária Municipal Piauí-anos de 1990, 1997, 2003 e 2009. Rio de

MACAMBIRA, D. M. Piauí: uma visão sumária da economia e da sociedade. In: Carta CEPRO. Teresina, v. 18, n. 1, p.39-65, jan./jun. 2000.

MATALLO JUNIOR, H. Indicadores de Desertificação: histórico e perspectivas. Brasília: UNESCO, 2001. 80p.

NIMER, E. Desertificação: realidade ou mito? Revista Brasileira de Geografia. Fundação Instituto Brasileiro de Geografia e Estatística, ano 50, n. 1, p.7-39, jan./mar. Rio de Janeiro: IBGE, 1988.

PIAUÍ. Gabinete do Governador. Palácio de Karnak. Projeto de Lei Complementar $n^{o}$ 004, de 14 de fevereiro de 2006. Estabelece o Planejamento Participativo Territorial para o Desenvolvimento Sustentável do estado do Piauí e dá outras providências.

PNUD - Programa das Nações Unidas para o Desenvolvimento. Atlas do Desenvolvimento Humano no Brasil 2013 (Com dados dos Censos 1991, 2000 e 2010). Disponível em: www.pnud.org.br. Acesso em dezembro de 2013.

RODRIGUES, M. I. V. A propensão a desertificação no Estado do Ceará: análise dos aspectos agropecuários, econômicos, sociais e naturais. Dissertação (Mestrado em Desenvolvimento e Meio Ambiente) - Programa Regional de Pós-Graduação, Fortaleza - CE, 2006.

SILVA, J. P. S. Impactos ambientais causados por mineração. Revista Espaço da Sophia, $\mathrm{N}^{\mathrm{o}} 08$, mensal, ano I, novembro/2007.

SOARES, D. B. Degradação ambiental no semiárido pernambucano: contribuição ao estudo da desertificação. Dissertação (Mestrado em Desenvolvimento e Meio Ambiente). Universidade Federal de Pernambuco, Recife-PE, 2012.

TRICART, J. Ecodinâmica. Rio de Janeiro, IBGE, Diretoria Técnica, SUPREN, 1977. 
USGS - United States Geological Service (Serviço Geológico dos Estados Unidos). Earth Explorer - Collection- Landsat Archive. Disponível em http://earthexplorer.usgs. gov/. Acesso em janeiro de 2015.

Francílio de Amorim dos SAntos

Doutorando em Geografia pela Universidade Estadual do Ceará e Mestre em

Geografia pela Universidade Federal do Piauí. Atualmente, é docente do Instituto Federal de Educação, Ciência e Tecnologia do Piauí / Campus Piripiri.

Av. Rio dos Matos, S/N, Bairro Germano, CEP: 64.260-000. Piripiri - PI.

E-mail: francilio.amorim@ifpi.edu.br

Cláudia Maria Sabóia de Aquino

Doutora em Geografia pela Universidade Federal de Sergipe e Mestre em

Desenvolvimento e Meio Ambiente pela Universidade Federal do Ceará.

Atualmente, é docente do Departamento de História e Geografia da Universidade

Federal do Piauí / Campus Universitário Ministro Petrônio Portela.

Centro de Ciências Humanas e Letras (CCHL), S/N, Bairro Ininga. CEP: 64.049550. Teresina - PI.

E-mail: cmsaboia@gmail.com

Recebido para publicação em maio de 2016 Aprovado para publicação em janeiro de 2017 